MANAGEMENT, ALGEMEEN - BEDRIJFSPROCES, ALGEMEEN - AUTOMATISERING, COMPUTER

\title{
Gewenste aanpak van het millenniumprobleem in middelgrote organisaties
}

\author{
Ir. P. Hagedoorn
}

\section{Inleiding}

De millenniumproblematiek, jaren geleden begonnen als IT-probleem, begint eindelijk door te dringen tot de agenda van het algemeen management van organisaties. Waar linanciële verstoringen in de bedrijfsvoering altijd onmiddellijk de volle aandacht opvragen, worden ITproblemen nog meestal beschouwd als 'loodgieters"-problemen die maar door de desbetreffende technische dienst moeten worden opgepakt. Het millenniumprobleem zorgt ervoor dat nu het volle besef doorbreekt dat de afhankelijkheid van IT in vrijwel ieder bedrijf zodanig is dat bedrijfsvoering zonder IT ondenkbaar is. Wie zijn zaken niet op orde heeft wordt in zijn continuïteit bedreigd. maar ook: degene die er snel bij is, kan een enorm concurrentievoordeel behalen. Hoe moet met name de middelgrote organisatie aankijken tegen de millenniumproblematiek. hoe schift zij waan van werkelijkheid, hoe voorkomt zij dat nodeloos kosten worden gemaakt, maar ook: hoe voorkomt zij nodeloze risico's door onderschatting van de problematiek?

\section{Wat is de millenniumproblematiek?}

De oorzaak van het probleem mag bekend worden verondersteld: in de jaren zestig werden jaartallen met (de laatste) twee getallen gerepresenteerd in computerprogramma's. Dat spaarde (toenmalig dure) geheugenruimte uit en de programma`s zouden tegen het jaar 2000 allang

Ir. P. Hagedoorn is hoofd projectbureau Millennium Platform. Daarnaast vervult hij enkele bestuurlijke functies en is hij commissaris bij het Nutsbedrijf Haarlemmermeer. vervangen zijn door nieuwe. Op het moment dat programmatuur met jaartallen voor en na de eeuwwisseling werkt en er bewerkingen mee worden uitgevoerd (aftrekken, vergelijken, op jaartal ordenen) gaat het mis. Prognoses worden verkeerd berekend, leeftijden of looptijden blijken negatief te worden, onderhoudsdata blijken te verlopen e.d. Wie beseft dat inmiddels vrijwel iedere organisatie in de praktijk grote delen van de administratie (financiën, salarisverwerking, personeelsdossiers, brievenafwikkeling, logistiek/voorraad) afwikkelt via computerprogrammatuur en de daarachter gelegen databases, begrijpt wat er allemaal mis kan gaan. Daarnaast is er het probleem van het schrikkeljaar. Een eeuwjaar is in principe geen schrikkeljaar, maar het jaar 2000 juist wel. Ten slotte blijkt dat het getal 99 (of 999, of 9999) in computers vaak andere betekenissen heeft (zogenaamde defaultwaarde) met als effect: het stoppen van bepaalde computeractiviteiten of het melden van een storing. Dit verschijnsel zal zich onder meer voordoen op 1 januari 1999, maar ook op 9 september (negende maand) 1999. Strikt genomen geen millenniumprobleem, maar wel iets om rekening mee te houden.

Een foutieve aanname is dat het hoofdzakelijk om een computerprobleem zou gaan. In ieder geval betreft het vrijwel alle computerprogranmatuur, computers en netwerken. Maar dat is maar de helft van het probleem, en het minst riskante deel. Genoemde programmafouten zijn namelijk ook gemaakt in alle programmatuur die als basis dient voor de vervaardiging van chips in elektronische apparatuur. In de jaren zestig is massaal begonnen met de vervaardiging van chips voor allerlei apparatuur, variërend van 
videorecorder tot ruimteraket en alles daartussen. In tientallen procenten van deze chips zitten datumfuncties die, afhankelijk van het apparaat zichtbaar of onzichtbaar, wel of niet gebruikt worden. Het gaat om de zogenaamde embedded systemen, waar langzamerhand de hele moderne samenleving in haar 24-uurs-economie op gebaseerd is. Allerlei 'just-in-time'-systemen en wereldomvattende netwerken zijn afhankelijk van het goed functioneren van deze tijdgestuurde apparaten. Een willekeurig voorbeeld: een vliegtuig (vol embedded systemen) wordt gevuld met kerosine (aangeleverd met een vrachtauto aangestuurd door een datumafhankelijk logistiek systeem) en gaat vliegen (via een datumafhankelijk air traffic control systeem) op basis van een passagierslijst (datumathankelijk). In zo'n keten van een transportsysteem is alles afhankelijk van het goed functioneren van alle onderliggende systemen, anders mag er niet gevlogen worden. Maar hetzelfde geldt voor vrijwel alle activiteiten in de moderne, maar o zo kwetsbare samenleving. Schattingen van Gartner, een Amerikaans internationaal IT-onderzoeksbureau, geven aan dat 'enkele procenten' van alle PLC's (Programmable Logic Circuits, de chips die geprogrammeerd kunnen zijn met een datumgestuurd onderdeel) dienst zullen weigeren of foutieve data of getallen zullen produceren. Er worden echter meer dan 4 miljard van deze PLC's per jaar geproduceerd en verwerkt in PC's, satellieten en alle andere denkbare elektronische apparatuur. En niemand, ook de producent vaak niet, weet welke PLC's goed of fout zijn en in welke apparatuur ze zijn gebruikt. Juist in complexe organisaties, zoals de procesindustrie of energieproductie, waar systemen systemen controleren, bestaat het risico dat onverwachte effecten optreden met stuur- en controle-elektronica. In termen van maatschappelijke risico's zijn deze embedded systemen veel belangrijker dan computersystemen voor administrątieve systemen.

Het millenniumprobleem laat zich het best vergelijken met een foute genenstructuur in een biologisch systeem dat collectief rond een bepaalde datum tot uiting komt. In sommige gevallen zal het organisme (de organisatie) het effect van het foute gen moeiteloos kunnen opvangen en vindt bijna geruisloos een hersteloperatie plaats. In een ander geval kan, bij dezelfde IT-genetische oorzaak, de gehele organisatie te gronde gaan.
Met name in grote organisaties leiden embedded systemen tot gigantische hersteloperaties. Oorzaak daarvan zit vaak in het feit dat testen van veel elektronica op dit aspect moeilijk of onmogelijk is en dat daarom veiligheidshalve gekozen moet worden voor integrale vervanging in bedrijfskritische situaties.

Een andere vergelijking met de biologische wereld is de grote ketenafhankelijkheid. Een organisatie kan zelf nog zo gezond zijn (oftewel het millenniumprobleem hebben opgelost in software, databases, hardware, embedded systemen), op het moment dat er gecommuniceerd of samengewerkt wordt met organisaties die het millenniumprobleem nog niet hebben opgelost. loopt de organisatie het risico zelf ook niet meer goed te kunnen functioneren. Dit zogenaamde ketenprobleem is een van de grote zorgen van koepel-/sectororganisaties en (internationale) overheden. Door het ketenprobleem ontstaan er risico's in (internationaal) transport, energieleveringen, financiële netwerken e.d.

\section{Wat zijn de risico's voor een organisatie?}

Het is moeilijk een risico-inschatting te maken met een algemene geldigheid voor organisaties. Waar de één veel of weinig risico's loopt in zijn financiële administratie, loopt de ander veel of weinig risico's in zijn productieproces, of beide. Absoluut zeker is dat de millenniumproblematiek een uiterst serieus probleem is; zonder twijfel het grootste, kostbaarste, meest algemene en wereldomvattende IT-probleem ooit, met een hoog risicogehalte voor duizenden organisaties. Zeker is ook dat alle organisaties, groot en klein, ermee te maken hebben op het moment dat er elektronische apparatuur staat opgesteld; en welke organisatie heeft niet ten minste een PC"? Alleen daarom al staat statistisch vast dat een deel van alle getroffen organisaties te laat zal starten, of te laat is gestart, en dat deze organisaties in de problemen zullen komen. Zij zullen daarom vrijwel meteen moeten gaan werken aan uitwijkscenario's. Een doorlooptijd vanaf nu van minder dan 400 werkdagen tot 1 januari $2000 \mathrm{zal}$ in veel gevallen immers onvoldoende blijken om alles getest en in orde te hebben. Risico's kunnen van 'binnen' komen (software en apparatuur is niet klaar of functioneert niet goed) maar ook van 
buiten. Vrijwel ieder bedrijf functioneert in een of meer ketens. Een deel van de inspanningen zal dus gelegen (moeten) zijn in het maken van afspraken met de relevante keten, zowel naar leveranciers (IT-leverancier, apparatenleveranciers, maar ook energieleverancier, leveranciers van diensten en producten) als naar klanten (andere afnemende bedrijven of consumenten). Organisaties die niet kunnen aantonen dat ze serieus bezig zijn kunnen ook risico's verwachten in de financiële omgeving. Banken zullen geen grote kredieten verschaffen en verzekeraars zullen geen polissen afsluiten of verlengen indien niet geloofwaardig aangetoond wordt dat de juiste maatregelen genomen worden. De accountant zal het management attenderen op de noodzaak tot het nemen van de juiste maatregelen, en het is niet denkbeeldig dat geen goedkeurende verklaringen door accountants worden afgegeven over het jaar 1998 indien deze aanwijzingen niet ter harte zijn genomen.

\section{Hoe pak je het millenniumprobleem aan?}

De grote bedrijven, met name financiële organisaties (banken), multinationals, zijn vaak reeds jaren met de problematiek bezig. Grote internationals die nog niet bezig zijn lopen zeer grote risico's wat betreft het overleven als organisatie. Uit een recent onderzoek (mei 1998) van PA Consulting Group blijkt dat de bewustwordingsgraad in Nederland bij de managers en beslissers inmiddels relatief hoog is $(97 \%)$, maar dat slechts tweederde van de organisaties adequaat aan de slag is. Dat wil zeggen: de organisatie heeft een projectleider, een budget en een planning en de inventarisatie is tenminste grotendeels rond. Een gestructureerde aanpak ziet men het meest bij de grote organisaties, het minst bij de kleinere. Eenderde van de organisaties aarzelt, neemt nog geen effectieve stappen of hanteert een overdreven optimistische planning en vergeet essentiële stappen in het proces. Waar de grotere organisaties de regel hanteren: 'oplossen dat probleem, wat het kost zien we later wel' is in kleinere organisaties meer de regel dat primair gemeend wordt dat er nog tijd genoeg is tot 1 januari 2000. Men beseft dan niet dat als alle organisaties zo denken, er in of na de zomer 1999 een zodanige druk op de IT- en installatiebranche ontstaat (en denk ook aan congestie in levering van millenniumbestendige apparaten) dat ook zeer vitale systemen onmogelijk meer op tijd aangepast kunnen worden. Daarnaast speelt veel meer dan bij grotere bedrijven het kostenaspect een rol. De ervaring is dat IT-projecten vrijwel altijd uitlopen, maar dit is nu net een project dat op tijd af moet zijn, althans voor de bedrijfskritische systemen.

\subsection{Primaire bedrijfsprocessen en maatschappelijke risico's}

Omdat ook grote organisaties inmiddels ontdekken dat niet alles op tijd af kan zijn geldt altijd de regel: focus op de primaire of vitale bedrijfsprocessen en op die zaken die kunnen leiden tot maatschappelijk (onaanvaardbaar) risico. Om deze reden hamert het Millennium Platform erop dat het millenniumprobleem een zaak is van het hoogste management. Vallen bepaalde bedrijfsfuncties uit, dan kan er immers een maatschappelijk risico ontstaan. Het hoogste management dient vast te stellen wat die primaire bedrijfsfuncties zijn. In veel gevallen is overleg in breder kader, branche- of sectoroverleg, of overleg met de overheid en toezichthoudende instanties nodig om de juiste prioriteiten vast te stellen.

\subsection{Projectaanpak en noodscenario's}

In vrijwel alle gevallen geldt dat een projectstructuur nodig is, waarbij een zware-projectleider wordt benoemd met de juiste bevoegdheden en budget, die direct entree heeft bij het hoogste management. De projectleider hoeft geen specifiek IT-technische achtergrond te hebben. Belangrijker is dat hij naast generalist (het gaat ook om contracten en externe onderhandelingen, om het kennen van de interne bedrijfscultuur) in staat is de tamelijk rigide planning daadwerkelijk te halen en alarm slaat als zich onverwachte tegenslag voordoet hetzij in de eigen organisatie, hetzij in externe ketens. Op basis van door eindverantwoordelijk management vastgestelde prioriteiten en budgetten zullen vaak onorthodoxe maatregelen nodig zijn om de onwrikbare einddatum tijdig te halen. De projectleider start met het maken van een volledige inventarisatie van alles wat een serieus probleem kan geven. Vervolgens zal in een analysefase vastgesteld moeten worden wat hoe moet worden aangepakt. Met name moet worden vastgesteld wat per se af moet zijn voor 
1 januari 2000 (of 1 januari 1999, vanwege het ' 9 '-probleem). In dit stadium dient reeds gestart te worden met uitwijkscenario's. Immers, nu reeds kan vaak vastgesteld worden waar door hetzij interne oorzaken, hetzij externe problemen calamiteiten kunnen optreden. Omdat het effectueren van uitwijkscenario's een project op zich is, ontstaat veelal op dat moment een parallelproject als schaduw of spiegel van het algemene project. Verder zal de projectleiding zorgvuldig moeten vastleggen wat de aangetroffen situatie is wat betreft contracten van allerhande producten en systemen. Immers, het devies is wel: ga primair het probleem oplossen en ga pas later eventuele juridische gevechten aan met de omgeving in de keten, maar dat neemt niet weg dat het wenselijk is zorgvuldig alles vast te leggen (bijvoorbeeld brieven aan leveranciers en klanten) wat later van belang kan zijn bij eventuele geschillen.

De projectleider zal na de analyse een planning maken voor de concrete uitvoering inclusief testen en implementatie. Het probleem van deze fase is hoofdzakelijk de systematische onderschatting van een drietal zaken. Het testen (duurt altijd langer dan gedacht; veelal meer dan 50\% van de doorlooptijd van het gehele project is nodig voor testen vanaf productniveau tot en met complete geïntegreerde systemen), het tijdig verkrijgen van de juiste capaciteit (kennis en 'handen') en het tijdig verkrijgen van elektronica of apparatuur. Naarmate de tijd vordert wordt een steeds grotere krapte aan deskundigheid op de markt verwacht en zal blijken dat essentiële software of apparatuur niet meer op tijd geleverd of geïnstalleerd kan worden.

\subsection{Millenniumbestendigheid en bestuurlijke verantwoordelijkheid}

De vraag is natuurlijk op welk moment millenniumbestendigheid is bereikt en welke zekerheden daarover bestaan. In alle gevallen is het wijs om een externe organisatie een audit te laten uitvoeren. Die audit moet dan niet alleen aandacht besteden aan de interne gereedheid maar ook aan ongebruikelijke zaken zoals het functioneren van de bedrijfsketens, de uitwijkplannen e.d. Als het goed is blijkt uit de audit dat de producten millenniumbestendig zijn (bijvoorbeeld voorzien van het Millenniumlabel of van een harde garantie of een testrapport van de leveran- cier), dat niet alleen producten maar ook complete samenhangende systemen getest zijn, dat uitwijkplannen opgesteld en geoefend zijn e.d. Dan nog blijft de hamvraag: wie garandeert dat 'het' werkt? Een externe auditeur zal, eventueel op vooraf met elkaar afgesproken meetcriteria, hoogstens vast kunnen stellen dat zorgvuldig alles is gedaan wat redelijker- (en desnoods onredelijker-)wijs van het management verwacht mag worden. De verantwoordelijkheid om 'ja' te zeggen tegen het dan bereikte ligt per definitie echter bij het eindverantwoordelijk management. Als alles gedaan is wat redelijk verwacht kan worden, bijvoorbeeld conform voorgaande denklijn, dan staat de organisatie bij eventuele ontsporingen juridisch sterker. Echter, als duidelijk is dat het management nodeloos zaken heeft laten liggen, die nu eenmaal horen bij behoorlijk bestuur dat kennis genomen heeft van de millenniumproblematiek, dan kunnen er nog interessante gerechtelijke uitspraken komen. Inmiddels is duidelijk dat banken of verzekeringen dan niet zullen bijspringen. Laten we hopen dat dat soort gevallen Nederland zoveel mogelijk bespaard blijft. Het uit te brengen rapport van de PA Consulting Group (oktober) zal hopelijk uitwijzen dat een hoog percentage van de organisaties aan de slag is.

\section{Wat doet het Millennium Platform?}

Het Millennium Platform heeft als algemene doelstelling bij te dragen aan en toe te zien op het goed blijven functioneren van de maatschappelijke processen bij de overgang naar het jaar 2000. Deze algemene doelstelling vertaalt zich naar een drietal hoofdtaken.

Allereerst moet het Platform zorgen dat er een behoorlijk bewustwordingsniveau is. Deze taak is inmiddels behoorlijk gevorderd, zoals ook blijkt uit hiervoor aangehaald onderzoek van de PA Consulting Group. Op deelgebieden (het besef dat embedded systemen zo belangrijk zijn en het besef dat elektronische ketens en bedrijfsketens zo belangrijk zijn) moet nog een verdiepingsslag plaatsvinden, met name bij kleinere organisaties (MKB, lagere overheden).

Als tweede hoofdtaak wordt gezien het bemiddelen tussen organisaties. Hier gaat het met name om het zorgen dat organisaties die de 
problemen moeten oplossen daartoe ook in staat zijn. Dit betekent het (doen) maken en distribueren van een adequaat arsenaal aan informatie (folders, voorlichtingsboekjes, tools, Internet, call center, presentaties) en zorgen dat er voldoende arbeidskrachten zijn (actie Nationaal Appèl waarop meer dan 14.000 reacties binnenkwamen, gecoördineerd door Arbeidsvoorziening met deelname van 30 IT - en uitzendbedrijven). Omdat het onmogelijk is voor het Millennium Platform om alle organisaties die vragen hebben individueel te bereiken, is een sector- en regiostructuur opgezet. Via de sector/branche-structuur (gebaseerd op de indelingen van VNO-NCW, MKBNederland en overheid) worden alle organisatieverbanden bereikt met voorlichtingsbijeenkomsten. Alle sector/branche-organisaties is gevraagd op te treden als millenniuminformatiepunt naar de leden van de sector/branche-organisatie, waarbij de sector/brancheorganisatie als 'frontoffice' en het Millennium Platform als 'backoffice' functioneert. Via deze opzet is het Platform erin geslaagd iedere (georganiseerde) organisatie een 'informatiekanaal' aan te bieden. Van al deze circa 400 sectoren en branches zijn er circa 15 bestempeld als 'vitaal'. Deze door de overheid benoemde sectoren worden als super-vitaal beschouwd voor het goed functioneren van de maatschappij. Voorbeelden: energie, waterhuishouding, sociale zekerheid, transport, zorgverlening, alarmorganisaties e.d. Voor al deze sectoren zijn speciale activiteiten gepland en uitgevoerd. zoals pilot-projecten, het inschakelen van toezichthoudende organisaties (arbeidsinspectie, inspectie volksgezondheid, dienst stoomwezen e.d.) en het vormen van subplatforms (energie en zorg). Bij de bemiddelingsfunctie hoort ook het actief inschakelen van "intermediaire organisaties': banken, verzekeringsbedrijven, accountants, technische branches als FENIT, UNETO, VNI, 't Instrument e.d. Zij allen staan in nauw contact met het Platform, en plannen acties naar hun klanten ter informatie en ondersteuning. Naast deze op sectoren toegesneden aanpak is een regiocampagne ontwikkeld. Samen met Kamers van Koophandel, ondersteund door provinciebesturen (Commissarissen van de Koningin) en samen met veel van bovengenoemde instellingen. maar bijvoorbeeld ook Syntens (voormalige Innovatiecentra) wordt gepoogd regioverbanden te ontwikkelen. In deze verbanden kan op regioniveau ingespeeld worden op de problematiek (bijvoorbeeld samenwerking om regioketens aan te pakken op gebieden als transport, energie, watervoorziening e.d.), kunnen regiopunten van Arbeidsvoorziening bereikt worden om millenniumpersoneel aan te trekken. Een aparte actie in het kader van de 'bemiddeling' is de ontwikkeling van een Millenniumlabel dat komende maanden door een aantal belangrijke producenten van IT-producten gevoerd gaat worden om afnemers te informeren over de mate van millenniumbestendigheid van de producten. Belangrijk onderdeel van de bemiddeling is natuurlijk dat de Platformorganisatie een aantal werkgroepen heeft, onder andere op gebieden als ICT (Softwarehuizen, hardwareleveranciers), embedded systemen, juridische vraagstukken, communicatie waar door alle sectoren en branches op gesteund kan worden. Deze werkgroepen 'verversen' ook regelmatig de informatie op Internet en zorgen ervoor dat de via Internet of het call center gestelde vragen adequaat worden afgewikkeld.

De derde hoofdtaak van het Platform is het monitoren van de voortgang in Nederland door middel van onderzoek. Daar waar sectoren, groepen, achterblijven, of daar waar blijkt dat bepaalde onderwerpen onderbelicht zijn, wordt actie ondernomen ter verbetering. Uit deze activiteit moet voortkomen dat later in 1998 en in 1999 organisaties en sectoren zelf aan het bredere publiek kenbaar gaan maken dat de zaken in orde zijn, dat we verzekerd zullen zijn van functionerende elektriciteitssystemen, functionerende transport- en financiële systemen, dat we kunnen rekenen op onze ziekenhuizen e.d. Een zorg is overigens de internationale situatie. Immers ook als in Nederland de belangrijkste zaken goed functioneren, blijven we afhankelijk van de internationale omgeving waarin Nederland is ingebed. Ook daaraan wordt door het Platform steeds meer aandacht besteed, hoewel op dit gebied met name de overheid natuurlijk een belangrijke rol speelt.

\section{Slot}

Met de hiervoor beschreven benadering hoopt het Millennium Platform te bereiken dat het $M K B$ in Nederland via allerlei kanalen geïnformeerd en geholpen wordt om tijdig de problemen de baas te kunnen. Een belangrijk aspect in deze problematiek is dat een sfeer ontstaat waarin 
bedrijven open zijn over het feit dat ze millenniumproblemen hebben (het is een gemeenschappelijk probleem) en dat men elkaar helpt (ketens) bij het tijdig oplossen. Niemand is gebaat bij een situatie waarin organisaties elkaar zodanig harde garanties vragen (die niet gegeven kunnen worden) dat het probleem escaleert tot allerlei rechtszaken. Dankzij de hoge organisatiegraad in
Nederland is er nog steeds een goede kans dat de meeste organisaties tijdig hun zaken op orde hebben en dat er geen domino-effecten optreden. Het is dan echter wel zaak dat organisaties, ook kleinere organisaties, nu direct en concreet aan de slag gaan om hun meest kritische systemen degelijk aan te pakken. 